\title{
A homemade endoscopic guillotine strikes again: removal of a nasogastric tube mysteriously knotted in the proximal third of the esophagus
}

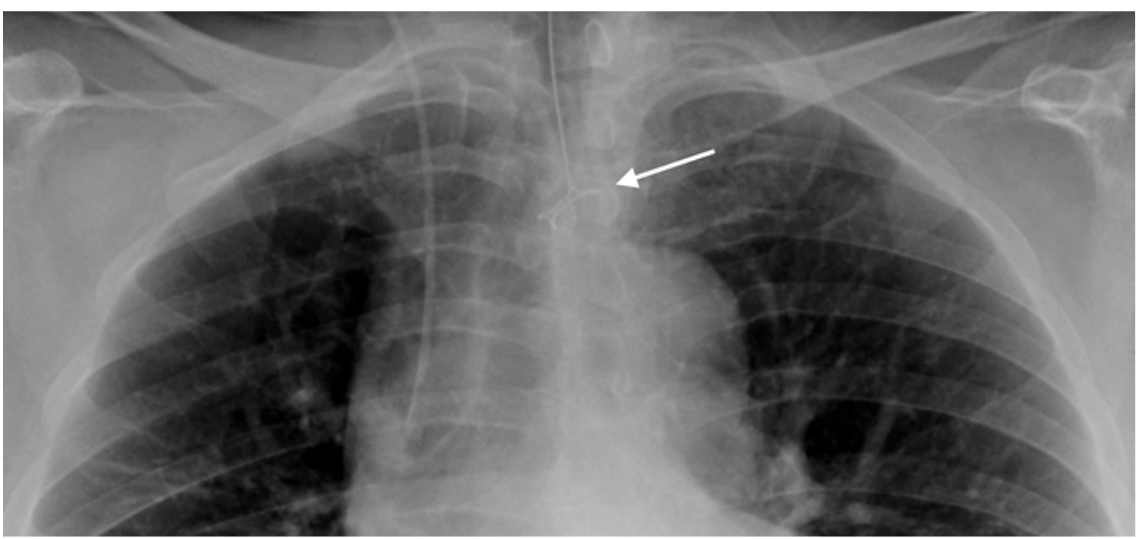

- Fig. 1 Chest radiograph showing the nasogastric tube forming a knot (arrow) in the upper third of the esophagus.

A 63-year-old woman with a past history of gastric bypass a few years ago was referred to our hospital with a mechanical ileus. A 14-Fr Salem nasogastric tube (NGT) was already in place for abdominal decompression at the time of admission. An ileal resection including a Meckel's diverticulum was performed with an ileoileal laterolateral mechanical anastomosis. Postoperatively NGT removal was impossible owing to strong resistance and the patient experiencing thoracic pain. A chest radiograph (\$Fig. $\mathbf{1}$ ) and an upper gastrointestinal endoscopy ( Fig.2a) showed coiling of the distal end of the tube, which had formed a knot in the proximal esophagus. Endoscopic removal of the NGT was attempted with the patient under general anesthesia. The NGT knot was pushed down into the gastric pouch to give more space for endoscopic maneuvers but, despite this, the knot could not be untied.

It was therefore decided to cut the knot using an "endoscopic guillotine," as has been previously described for plastic stents [1] and a 14-Fr NGT [2]. In order to avoid accidental interposition of gastric, esophageal, or small-intestinal mucosal wall during the cutting phase, we opted for a technical variant that has previously been described for plastic stents [3] and migrated gastric band trimming [4,5], A sphincterotome (CleverCut3V; Olympus) was used to thread a 0.035 -inch, 450-cm, straight-tip guidewire (Dreamwire; Boston Scientific) through the knot in the NGT ( $\triangleright$ Fig. $\mathbf{2}$ b) and the distal end of the guidewire was retrieved using a standard biopsy forceps (Endojaw Large; Olympus). Both ends of the guidewire were then locked into a mechanical lithotripsy device (Olympus) (\$ Fig. 3 ) and the crank handle of the lithotripter was gradually turned until the NGT was completely transected ( $\downarrow$ Video 1 ). The proximal part of the NGT was gently removed by pulling it through the patient's nose. The three remaining sections of the NGT were retrieved using a raptor grasping device (Steris) (\$ Fig.4). No relevant iatrogenic lesions were observed at endoscopy, and no peri- or post-procedural complications occurred.

Endoscopy_UCTN_Code_CPL_1AH_2AJ

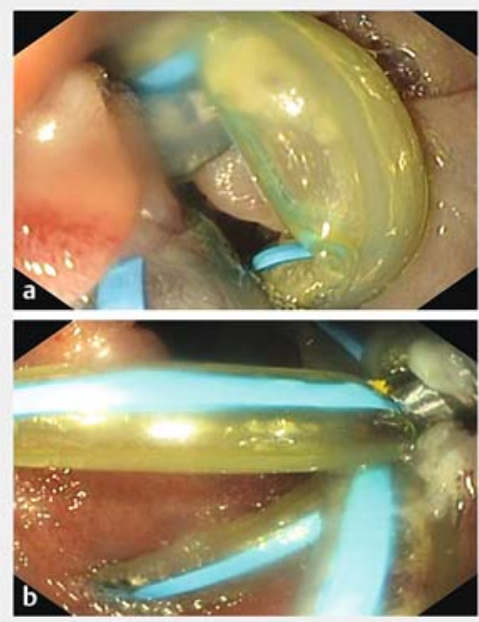

Fig. 2 Endoscopic views showing: a the knot in the nasogastric tube; $\mathbf{b}$ the guidewire wrapped around the knot.

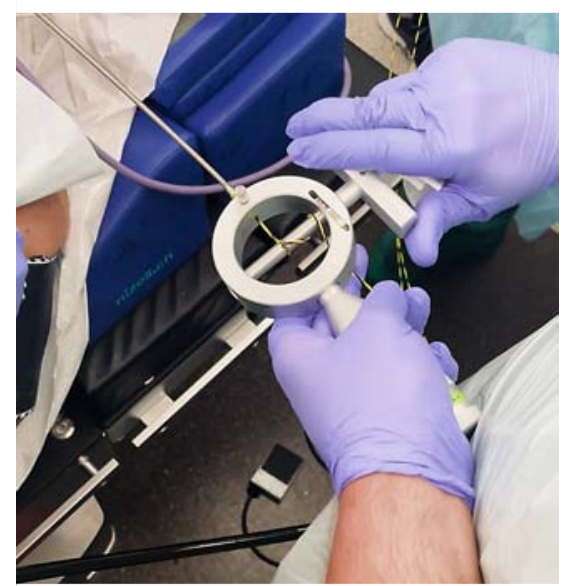

Fig. 3 Photograph of the crank handle of the lithotripter being turned during the procedure.

\section{Competing interests}

The authors declare that they have no conflict of interest. 


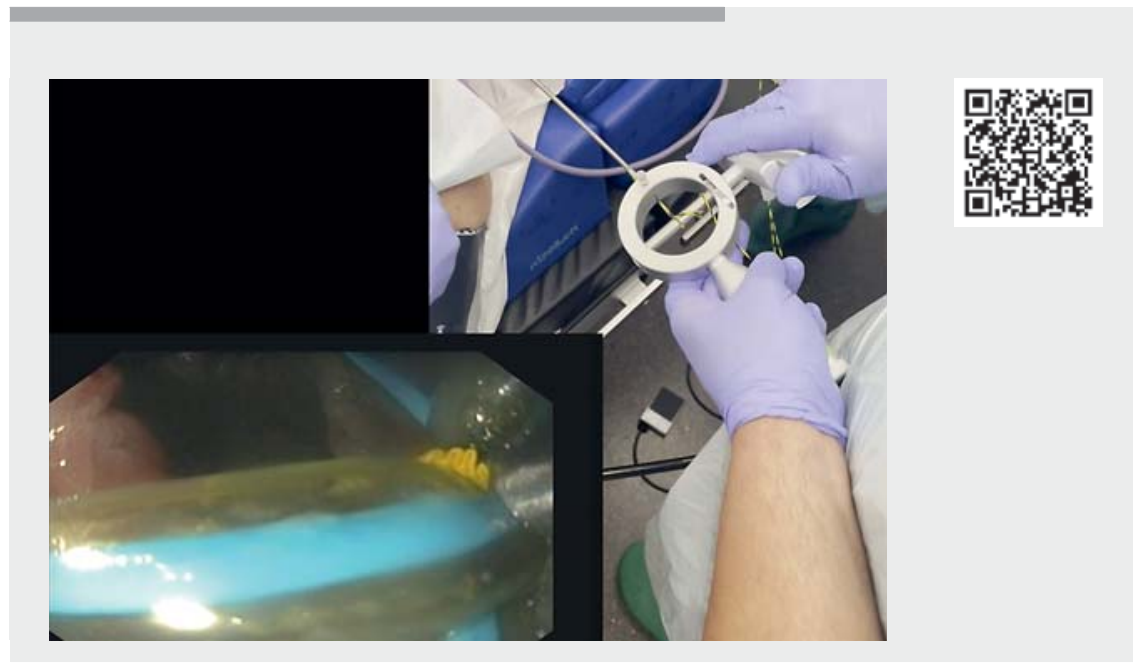

$\checkmark$ Video 1 A sphincterotome was used to thread a guidewire through the knot in the nasogastric tube (NGT) and the end of the guidewire was retrieved, with both ends then being locked into a mechanical lithotripsy device. The crank handle was turned until the NGT was transected and the parts of the NGT were then removed through the patient's nose and mouth.

The authors

Fabio Pinto do Couto ${ }^{1}$, Aurélie Cavin ${ }^{1}$, Olivier Pittet $^{1}$, Paraskevi Archanioti ${ }^{2}$, Sébastien Godat $^{3}$, Domenico Galasso ${ }^{2,3}$ (๑)

1 Department of Surgery, Riviera-Chablais Hospital, Rennaz, Switzerland

2 Gastroenterology Unit, Riviera-Chablais Hospital, Rennaz, Switzerland

3 Department of Gastroenterology and Hepatology, Vaud University Hospital Centre (CHUV), Lausanne, Switzerland

\section{Corresponding author}

\section{Aurélie Cavin, MD}

Department of Surgery, Riviera-Chablais Hospital, Route du Vieux Séquoia 20, Rennaz (Vaud), CH1847, Switzerland aurelie.cavin@hopitalrivierachablais.ch aurelie.cavin@chuv.ch

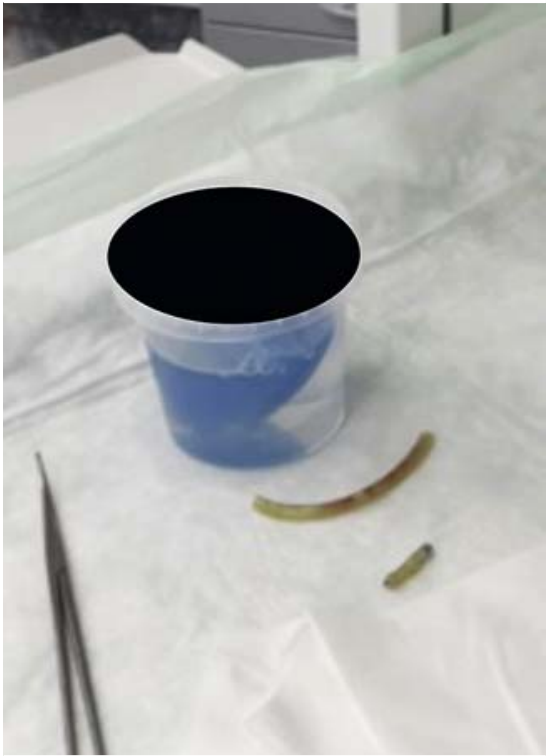

- Fig. 4 Photograph showing two of the three pieces of the nasogastric tube that were removed through the patient's mouth.

\section{ENDOSCOPY E-VIDEOS}

https://eref.thieme.de/e-videos sertion tailoring of plastic biliary stents: A novel technique. Endoscopy 2006; 38: 856

[2] Galasso D, Tringali A, Riccioni ME et al. Use of a homemade endoscopic guillotine to cut through a nasogastric tube inadvertently sutured to a colon-gastric anastomosis. Endoscopy 2013; 45: E413-E414

[3] Mutignani M, Salerno R, Perri V et al. Removal of a doubly impacted plastic stent: A new technique. Endoscopy 2008; 40: E215-E216

[4] Gutiérrez JP, Acosta F, Geninazzi H et al. Removal of a migrated gastric band using the Soehendra bile stone lithotripter. Endoscopy 2013; 45: E371-E372

[5] de Sousa Damião F, Noronha Ferreira C, Nogueira F et al. Endoscopic removal of a migrated gastric band. Endoscopy 2021; 53 : S189

Bibliography

Endoscopy 2022; 54: E676-E677

DOI 10.1055/a-1738-9112

ISSN 0013-726X

published online 18.2.2022

(c) 2022. Thieme. All rights reserved.

Georg Thieme Verlag KG, Rüdigerstraße 14,

70469 Stuttgart, Germany
This section has its own submission website at https://mc.manuscriptcentral.com/e-videos 